\title{
Recusas e empréstimos da repetição na performance'
}

\section{Refusals and borrowings of repetition in performance}

\author{
Renan Marcondes ${ }^{2}$ \\ DOI 10.265।2/museologia.v9il7.
}

\begin{abstract}
Resumo
A partir de autores como Peggy Phelan, Philip Auslander,Amelia Jones e Rebecca Schneider, o artigo aproxima o termo performance da noção de repetição, lançando luz sobre alguns dos principais debates suscitados pela arte da performance em relação às suas possibilidades de documentação e arquivo. Busca-se deslocar a usual relação da performance com o tempo presente, justapondo posições antagônicas que evidenciem a relação complexa que a performance tem com documentos e arquivos.
\end{abstract}

\section{Palavras-chave}

Performance. Repetição. Documentação. Arquivo. Memória.

\begin{abstract}
Based on authors such as Peggy Phelan, Philip Auslander, Amelia Jones and Rebecca Schneider, the article brings the term performance closer to the notion of repetition, shedding light on some of the main debates raised by performance art in relation to its possibilities of documentation and archive. It seeks to displace the usual relationship between performance and the present time, juxtaposing antagonistic positions that highlight the complex relationship that performance has with documents and files.
\end{abstract}

\section{Keywords}

Performance. Repetition. Documentation. Archive. Memory.

O imaginário comum em relação à performance (incluindo aqui a arte da performance e as artes performativas em geral, como teatro e dança) tende a situá-la como antagônica a qualquer força que a desloque do tempo presente. Nesse sentido, qualquer tentativa de arquivamento, reprodução ou documentação da performance seria uma traição ou diminuição de sua forma original. Porém, como coloca Catherine Wood (2018: 28, tradução nossa), curadora de performance da Tate Modern, "a recuperação dessa história da performance e a preservação de trabalhos performativos é uma preocupação atual de muitas instituições”. Por mais escassa que ainda seja essa preocupação em instituições de arte brasileiras (com poucos casos, como o MAM e a Pinacoteca do Estado em São Paulo, que apenas recentemente passaram a integrar performances em seus acervos), Wood reforça o caráter global dessa situação, marcada por "um interesse maior e mais amplo em tradições vivas: a Organização das Nações Unidas para a Educação, a Ciência e a Cultura (UNESCO) começou a preservar 'herança cultural intangível' junto de monumentos e artefatos, por exemplo" (idem).

Como notado por esta presente edição, a crescente necessidade de historicização do que é produzido de forma efêmera ou intangível também altera as próprias práticas em performance, que passam a ser pensadas em diálogo com sua possibilidade de coleção, institucionalização e preservação. Ao contrário do "alto período entre os anos 1950 e 1970" (idem) no qual o corpo do artista era o local primordial das performances, as recentes práticas incorporam

I Esse artigo integra a pesquisa "Outros corpos: presença e performatividade para além do humano", financiada pela FAPESP no processo 2017/073।I-2.

2 Doutorando em Artes Cênicas na Escola de Comunicação e Artes da Universidade de São Paulo (USP). E-mail para contato: renancevales@gmail.com. ORCID: https://orcid.org/0000-000I-8650-4I5I. 
também o corpo do público em performances relacionais, contratam atores, delegam funções a grupos específicos ou são apenas virtualmente realizadas (BISHOP, 20I2). A crescente flexibilização e porosidade das práticas em performance parece contestar - ou ao menos alargar - a máxima de que "a única vida da performance se dá no presente" ou de que "a performance aparece como a arte do eu", como afirmaram respectivamente Peggy Phelan (2003: I55) e Josette Feral (20I5: I46), teóricas centrais no campo da arte da performance e do teatro contemporâneo.

A fim de sugerir que a performance, mesmo através da negação, tem uma relação direta com a repetição de suas práticas, esse artigo busca apresentar um debate central entre aproximações distintas da performance: uma corrente, de maior difusão, antagoniza a performance em relação às suas reproduções; enquanto a outra, desenvolvida principalmente a partir dos anos 1980, situa a performance como uma prática condicionada pela sua própria repetição e documentação. A segunda corrente não é apenas mais recente, mas também está imbricada com o que autores como Ana Javenski e Costin Costinas (2014: 7) chamam de uma "nova virada performativa", marcada pela já citada inclusão de acervos de performance em instituições e arquivos, mas também pelos crescentes usos do termo performance no campo político e econômico, o que cria um cenário ambíguo no qual as performances são ao mesmo tempo signo da "resistência da comercialização" do mundo da arte (ecoando seu surgimento nos anos 1960) e "produtos perfeitos para a economia da experiência imaterial" (idem).

Apesar de não abordarmos diretamente esse problema no artigo, é importante situar o potencial de apropriação da característica imaterial da performance nos nossos dias para que deixemos de entender sua recusa à documentação como um gesto de pura resistência política, como foi durante a segunda metade do século XX nos Estados Unidos e na Europa. Se hoje há uma "cooptação da performance, do poder performativo da performance (sua possibilidade de não apenas representar, mas de gerar efeitos e matérias, e fazer mundo) pela economia [...] crucial para entender como ideologias neoliberais encontram com o “capitalismo afetivo'” (LEPECKI, 20I6: 9, tradução nossa), pode-se pensar que a recusa determinada à documentação, mantendo o encontro presencial como valor maior, não é apenas um gesto de resistência, mas faz também parte do próprio mecanismo de produção de valor simbólico dessas obras efêmeras.

\section{Performance e documento: embates na linguagem}

Mesmo que sempre mutável, o atual significado corrente do termo performance se reporta "ao advento de uma nova categoria estética identificada com happenings, arte da performance, body art, acionismo e dança pós moderna - todas expressões artísticas que emergiram globalmente mais ou menos entre 1959 e 1979" (LEPECKI, 20I4: 8, tradução nossa). Esse movimento artístico pode ser entendido de forma ampla como "um modo de alargar a moldura ao redor do que era previamente considerado como trabalho artístico, para incluir também a presença ativa de seu criador e observadores" (WOOD, 2018: 8, tradução nossa). Por aproximar, na obra, o tempo de produção com o tempo de existência e observação da obra em si, as práticas da performance sempre tiveram uma relação conflituosa com o registro de suas práticas, pois para centrarem-se na presença e no encontro presente precisariam recusar em menor ou maior nível o caráter objetual subentendido na obra de arte. 
Assim, por um lado há a afirmação de que a arte da performance é compromissada com o "aqui e agora” (DE DUVE, 1983). Também como coloca Peggy Phelan (2003), sua única vida se dá no presente, sugerindo que há na performance uma força ontológica de resistência à economia de reprodução capitalista, em um dos mais paradigmáticos ensaios sobre a linguagem. Por outro lado, ainda quando a arte da performance se encontrava em suas primeiras décadas, "os artistas da performance que se interessavam em preservar seus trabalhos rapidamente tomaram consciência da necessidade de encenar para as câmeras (AUSLANDER, 20I3), promovendo uma série de práticas orientadas para a foto e para o vídeo. Se, no primeiro caso, "a documentação da performance através de fotografias ou vídeos é somente um estímulo para a memória" (PHELAN apud MELIN, 2008: 37), no segundo os usos e relações possíveis entre linguagens artísticas se expandem, incluindo ações feitas em espaços internos, sem público ou com públicos pontuais, ou em situações e contextos específicos.

Para Phelan, essa ontologia da performance a vincula ao gasto. Como coloca Eleonora Fabião (2019: 46, tradução nossa), "Phelan renova a discussão sobre a presença ao assinalar a desaparição como o referente performativo elementar", afirmando que a performance, através da criação de ações que nada deixam no mundo e que não restam, resiste à economia espetacular, à reprodução historiográfica, e à reprodução como dogma heteronormativo. Em Phelan, sempre que uma performance é documentada ela deixa de sê-la, e passa a participar de um sistema de circulação e reprodução do qual deveria recusar por princípio. Seu argumento visa situar as práticas em performance como um meio específico, distante tanto das outras artes performativas como o teatro e a dança (por romper com dramaturgias, representações e narrativas) quanto das artes visuais (por romper com dispositivos de produção, exibição e circulação de produtos).

Já Philip Auslander (20/3) afirma que é justamente porque os artistas da performance afirmam dispensar a repetição e sublinham a importância do evento, que todo registro ou documentação necessariamente se mesclará com a obra em si, perdendo o caráter autônomo de obra de arte e se reportando ao passado desse evento "importante". Sua argumentação, ao dividir os registros da arte da performance como documentais ou teatrais, surpreendentemente afirma o caráter teatral como inerente a esse tipo de registro, recolocando a performance no campo da representação que muitos artistas negaram (como o luso-brasileiro Antonio Manuel ao afirmar nos anos 1970 "eu quero atuar, não representar"). Já Auslander, fazendo contraponto a uma tradição de pensamento que vê o teatro como signo da falsidade e da ilusão a ser superada (iniciada em Platão e com ecos mais recentes em Clement Greenberg e Michael Fried), olha para obras clássicas da performance, hoje acessíveis apenas como documentos, para detectar sua teatralidade inerente.

Uma performance realizada sem a presença de público como Shoot (I97I), na qual o artista estadunidense Cris Burden leva um tiro no braço dentro de seu ateliê, convida-nos a ver seu registro como se estivéssemos lá, projetando a nossa presença naquele espaço e tempo passados, independentemente da distância temporal entre o acontecimento e a exibição do registro em vídeo da ação. Segundo Auslander (20l3), só podemos dizer que aquilo de fato aconteceu quando acordamos em imaginar conjuntamente que não houve manipulação alguma no conteúdo desse vídeo e desconsiderando qualquer outra hipótese em relação ao que não estava enquadrado (como a presença de uma equipe médica atrás das câmeras ou o uso de efeitos especiais). 
Se, nesse caso, o caráter teatralizado se daria pela própria situação reclusa da ação real, que nos obriga a acreditar em sua vivacidade apenas através de um tipo de reprodução, existem casos históricos nos quais a própria forma da obra a teatraliza, por figurar um evento impossível. A clássica imagem do Salto para o vazio (1960) de Yves Klein, que mostra o artista a se jogar do alto de uma casa ao encontro do chão, apesar de ser uma referência incontestável para a arte da performance e para as futuras inclusões do corpo de artistas nas suas próprias obras, é uma ação que nunca aconteceu de fato, tendo sido orientada para a câmera e dependente da posterior manipulação mecânica da imagem (Figura I). Hoje, seria uma imagem rapidamente enquadrada como fake news: caso pesquisado o evento real, chegar-se-ia ao que de fato foi fotografado: na primeira foto, uma rua vazia na qual o corpo do artista não está presente, e, em outra foto, Yves Klein a pular em direção a um grupo de amigos que seguram um colchão para receber seu corpo no chão. Posteriormente manipulada, a obra surge do encontro e manipulação entre duas imagens. Porém, não é a descoberta da versão oficial que deslegitima ou diminui a força da obra. Pelo contrário, a versão real é dispensável no que tange à força simbólica daquele homem a saltar em direção ao chão de concreto. Na perspectiva de Auslander, é uma operação teatral que sustenta a imaginação daquele conteúdo visto como um evento possível.

Figura I - As fotografias originais de Harry Shunk para Salto para o vazio (1960) de Yves Klein.

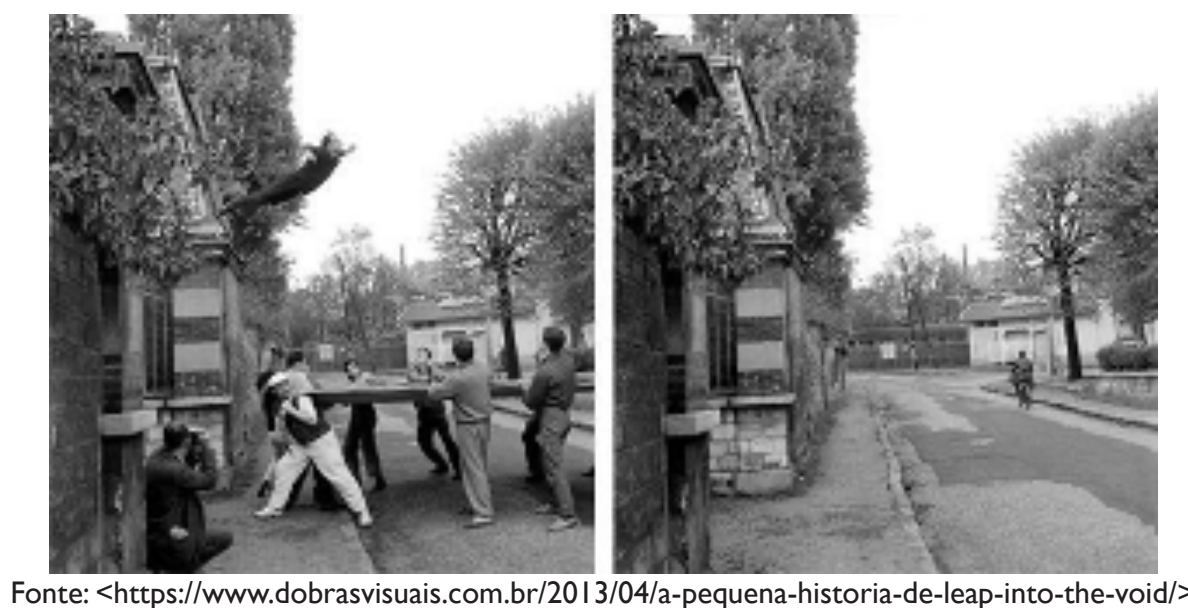

Escrita há quase trinta anos, a perspectiva notadamente melancólica de Phelan é ainda sedutora para se pensar a performance como meio específico justamente por ela se afirmar como embate direto ao sistema capitalista. Ao afirmar a irreprodutibilidade da performance como um fator positivo, convida-nos a desconsiderar tanto a extensa documentação dessas práticas desde seus primeiros experimentos nos anos 1950 quanto a extensa cadeia de técnicas, objetos, materiais e linguagem que possibilitam a cada performance se inscrever no presente. Em suma, ao afirmar o caráter único do evento como um contraponto à reprodução, Phelan se esquece do fato de que mesmo negada de forma mais radical na arte da performance, a repetição constitui as práticas de performance. Já Auslander nos convida a ver, a partir das próprias documentações, que toda performance se constitui nesse espaço vazio entre oficialidade do documento e representação, desestabilizando lógicas tradicionais de arquivo. E se teatralidade pode ser entendida, segundo a filósofa Juliane Rebentisch (2017: 103-105), como uma "distancia fundamental entre coisa e signo" e como "oscilação apa- 
rentemente indecisa entre literalidade e referencialidade", podemos pensar no espaço que se abre entre o evento e sua documentação como uma das forças características da performance.

\section{Performar de novo}

Outras concepções do termo "performance" parecem desafiar esse compromisso com a presença e com a efemeridade com a qual ele passou a se identificar após os anos 1960 no campo das artes. Seja pela ótica antropológica de Victor Turner ou pelo olhar teatral de Richard Schechner, outros importantes pensadores da performance, a performance se encontra em relação direta com rituais sociais, ou seja, com manifestações de valor simbólico culturalmente reconhecidos. Segundo Schechner (20II: I2), "algo é performance quando os contextos histórico e social, a convenção, o uso, a tradição, dizem que é”. Justamente por sua aderência ao tecido social, para ele as performances são "construídas a partir de pedaços de comportamentos, rearranjados e modelados de modo a produzir um efeito determinado." (SCHECHNER, 2003: 27), através do ritual ou do jogo. Pois como fica claro em uma de suas raízes etimológicas (ROACH, 1996: 3), o verbo francês parfounir (completar, concluir) indica que a ação da performance não apenas deve ser um fenômeno ocorrido e visível no presente, mas também finalizar um processo, efetivando uma transformação no mundo.

Mesmo na teoria dos "verbos performativos" do linguista J. L. Austin (1990) - central para a arte da performance ao teorizar verbos que sincronizam no tempo a relação entre falar e fazer (em casos como "eu aposto" ou "eu nomeio") - está contido esse dado cultural prévio para seu pleno funcionamento. Segundo o linguista, sem ou fora da instituição do casamento, emitir um performativo como "eu aceito" não cria nenhuma transformação efetiva no emissor ou receptor, tornando a emissão infeliz (AUSTIN, 1990: 39-40). É nesse sentido que a performance será, na visão de Joseph Roach (1996, tradução nossa), "sempre um substituto para alguma coisa que a preexiste", vinculando-se não apenas à repetição, mas à substituição inerente à tradição. $O$ autor sustenta que a performance se posiciona como "uma entidade ilusiva" que "precisa em vão aspirar tanto incorporar quanto substituir" (idem, grifo nosso). Sempre mediada por outra performance anterior a si mesma, cada performance que se realiza restaura determinadas convenções por transformá-las (enquanto supera outras através do esquecimento). Nessa perspectiva, não há como se advogar por um gesto inaugural, sendo apenas "graças a esse carácter repetitivo que se instaura a performatividade, oriunda de uma ficcionalidade que estabelece um protocolo de ressurgimento do mesmo enquanto outro em cada imagem", como afirma Delfim Sardo (2008: 3 I I) ao falar especificamente sobre performance nas artes. Nesse sentido, a performance poderia ser vista não como um meio que recusa sua reprodução, mas sim como uma forma específica de arquivo que não o entende como uma reprodução estável a ser preservada, mas como uma memória cultural que é repassada ao mesmo tempo em que é transformada e esquecida. É nesse caminho que Amelia Jones (2013) argumenta em mais de um texto sobre a impossibilidade de uma experiência sem mediação em qualquer tipo de produção cultural, inclusive no corpo a corpo da arte da performance. Segundo ela, ver uma ação performática ao vivo ou documentada apresenta uma clara diferença por conta da especificidade de apreensão, mas não indica que uma tem privilégio de verdade sobre a outra. Ao reforçar que o desejo de imediatismo 
Recusas e empréstimos da repetição na performance

é "historicamente específico e não epistemologicamente seguro", identificável como um "sonho modernista" (idem), a autora pensa a relação entre ação e documentação como uma afirmação do "caráter suplementar do corpo", como sintetiza abaixo:

\begin{abstract}
Usando um pós-estruturalismo feminista informado pela fenomenologia, meu argumento se baseia na leitura dessa subjetividade transfigurada por meio das obras em si (especificamente: as obras como vestígios documentais, e isso vale também para os eventos que presenciei "em pessoa"; vejo estes por meio da tela da memória, e eles se tornam documentais por direito próprio). Entendo performances de body art como encenações das subjetividades dispersas, multiplicadas e específicas do fim da era capitalista, pós-colonial e pós-moderna: subjetividades cuja existência é reconhecida sempre já em relação ao mundo de outros objetos e sujeitos; subjetividades que sempre já são intersubjetivas assim como interobjetivas. Especificamente, insisto que é precisamente a relação desses corpos/sujeitos com a documentação (ou, mais especificamente, com a representação) que aponta mais profundamente para o deslocamento da fantasia do sujeito modernista fixado, normativo e centrado, e, portanto, oferece um desafio mais dramático ao machismo, racismo, colonialismo, classicismo e heterossexualismo embutido nessa fantasia (idem).
\end{abstract}

Jones confere também às imagens (e seu potencial de circulação) poder de operar performativamente no mundo, transformando a própria visão dos sujeitos sobre seus corpos. A autora relembra como o poder performativo dos registros cria narrativas próprias e ficcionais, como o mito da automutilação genital do performer vienense Rudolf Schwarzkogler, em I966, criando um efeito de verdade sobre algo que nunca ocorreu a partir de uma série de fotos que não apenas eram encenadas, mas também posadas por outro artista. Como se pode perceber na produção dos anos 1980 e 1990 de artistas como Cindy Sherman e Gillian Wearing (na qual a superfície da foto e vídeo viram meios centrais para a manipulação do corpo, com próteses e máscaras de si mesmas), esse potencial performativo da imagem é cada vez mais usado como recurso pelos próprios artistas (Figura 2).

Figura 2 - Gillian Wearing. Self Portrait of Me Now in Mask. 20I I

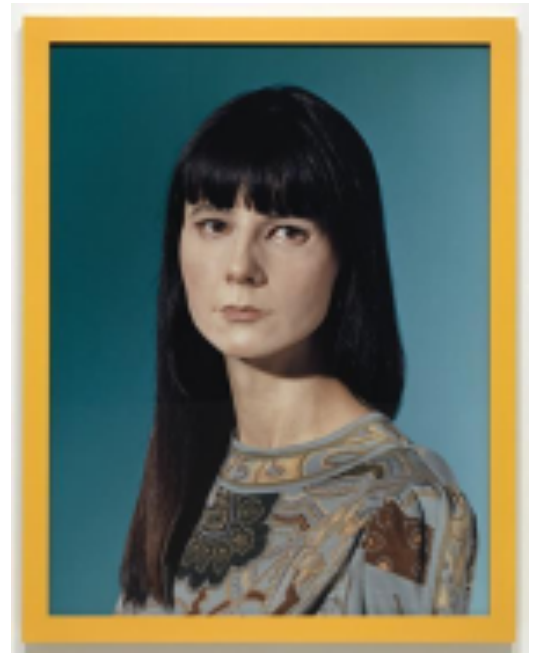

Fonte: <https://www.moma.org/collection/works//57603>. 
Se Jones se distancia do argumento de Phelan, Rebecca Schneider responderá de forma mais direta à sua afirmação da performance enquanto gasto, reinscrevendo a diferença que se dá na repetição como um elemento fundante tanto no arquivo quanto na performance. As bases da argumentação de Schneider vêm principalmente de Mal de Arquivo, texto de Jacques Derrida no qual o autor detecta um "fora" criado pelo próprio arquivo, uma "certa exterioridade" (200I: 14) na qual outros modos de memória poderiam se dar. $\mathrm{Na}$ visão do autor, o arquivo é "ao mesmo tempo o começo e o comando" (200I: II), contendo em si tanto uma ontologia ou história quanto um princípio de lei "onde se exerce a autoridade, a ordem social" (idem). Enquanto uma autoridade que estabelece propriedade do que sobrou a partir de um modo de organização, leitura e apreensão, deixa necessariamente um contingente fora de seu alcance.

Schneider é movida pela hipótese de que a afirmação de Phelan enquanto gasto depende da aceitação de determinado padrão de historiografia do arquivo, à qual a performance se contraporia. Dessa forma, ao se afirmar como gasto, a performance tomaria para si um lugar menor ou menos seguro que a "casa" oficial dada pelo arquivo: aparatada da lógica do arquivo e reafirmando- o como o modo "oficial" de guardar, seria impossibilitada de clamar também para si a produção de história. Pensar nessa linguagem como gasto seria aceitar uma posição determinada pela própria lógica arquivista que, para se consolidar, espera da performance que desapareça, negando validar práticas onde há transmissões parciais e difusas (narração oral, recitação ao vivo, gesto repetido e representação ritual, arte da performance, etc.) em favor daquilo que o arquivo valida como documento, ou seja,"restos discretos - material apresentado como preservado, como não-teatral, como 'autêntico', como 'si mesmo'” (SCHNEIDER, 20I2: $|4|$ ).

Agora, se a arte da performance se caracteriza pelo o que o arquivo não abarca - por ser não-original, indiscreta, contaminada - a autora sugere um contra modo de produção de arquivo, dissociado de uma visão nostálgica que pensa eventos do passado como fundadores ou originais em algum modo (e que, portanto, precisam ser resguardados como tal). De forma análoga à Roach, para ela só é possível pensar o passado como já diferente em si e nunca como evento fundante, uma vez que é composto pela restauração de um passado prévio a ele. O desafio da performance em relação ao arquivo não se dá por se situar fora de seu espectro. Pelo contrário, é criando dimensões de arquivo descompromissadas com a preservação segura de um passado que a arte da performance pode se provar como documento "através de uma reaparição confusa e eruptiva" (ibidem: I43).

É nesse sentido que parece se dar uma série de práticas bastante recentes de performance que se dão dentro de contextos institucionais: em "Biblioteca da Dança" de Jorge Alencar e Neto Machado, grupos de artistas assumem a função de livros humanos em bibliotecas de instituições, contando para o público sobre as peças que mais marcaram sua vida e criando um catálogo pessoal de obras que se transmitem apenas pelo afeto e pela oralidade, recusando registros oficiais em foto e vídeo (Figura 3); também as performances de Alexandra Pirici e Manuel Pelmus atualizam acervos de museus a partir da reprodução coreografada de pinturas e esculturas por dançarinos profissionais e amadores. Essas obras assumem que, como coloca Lepecki (2016: I l 6, tradução nossa), "toda tradução, todo carregar de um trabalho para uma sobrevida para além dos limites originais do trabalho, também reflete de volta ao original, mudando-o para sempre". 
Figura 3 - Biblioteca da Dança, de Jorge Alencar e Neto Machado (20।7).

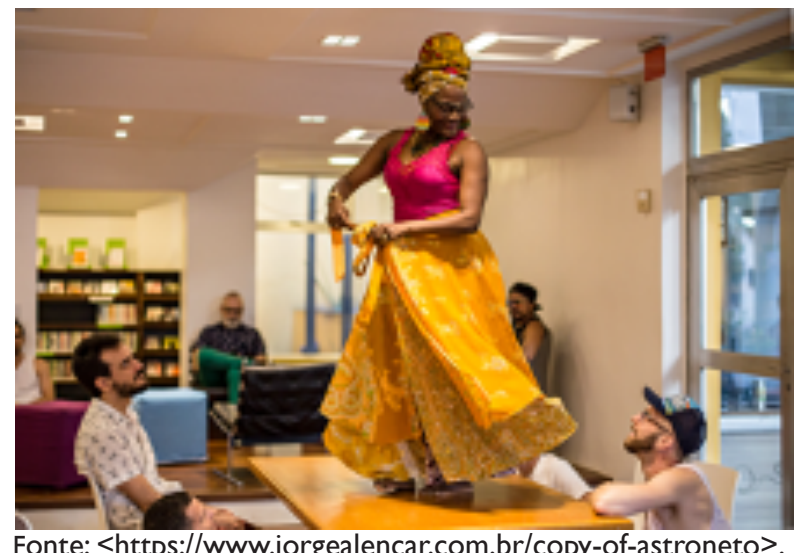

\section{Considerações finais: $o$ espaço entre}

Dentro desse extenso debate, Catherine Wood (op. cit,: 26) resume que "as duas aproximações polarizadas para performances do passado que definem esse território são as de Peggy Phelan e Philip Auslander:a primeira acreditando na presença única do evento ao vivo, na qual "se precisaria estar", o segundo argumentando que apenas a mediação do evento nos possibilita reconhecê-lo tal qual uma performance". Segundo ela, o curador Johnan Westerman sugere uma terceira aproximação "intermedial" que tem a ver com o espaço entre testemunha e documento, um espaço no qual a performance "descansa e vive". Essa parece a perspectiva mais instigante para se pensar a performance nos dias de hoje: enquanto foco sobre uma dessincronia temporal inevitável, que determinadas práticas de arquivo tentaram negar ou superar a partir de uma suposta verdade. No lugar dela, pensar que todo passado lembrado se constitui através de "[...] uma performatividade que não radica na verdade (nem na verdade do corpo, nem na verdade da presença, nem na verdade do sentido), mas numa possibilidade ficcional desenhada em processos de proximidade e distância, na relação com a utopia do tempo real ou no seu correlato construído a partir de processos performativos de documentação, e como representação da presença" (SARDO, 2008: 319).

A performance é uma prática que não se situa nem no presente imediato e nem no passado cristalizado, mas na evidenciação dos processos de repetição nos quais coisas, signos e ações voltam, mas provando-se um tanto diferentes. Nas artes, tanto sua documentação quanto sua prática ao vivo levam a limites o caráter de restauração dos gestos que fazem parte das práticas performativas, apresentando de modo alterado, hiperexposto, reduzido, evidenciado, ritualizado o que, de alguma forma, já foi visto. Assim, as práticas não fazem frente ou recusam a repetição, mas assumem o compromisso de a cada nova vez inscrever uma diferença fundamental.

Ao contrário de grande parte da teoria da performance, que reivindica uma impossibilidade documental pela 'pura presença' que é a natureza do performativo, deve acentuar-se, não a presença, mas os processos de representação: no centro do performativo, encontra-se sempre determinada forma de representar o corpo, a relação entre corpos, o espaço, relações políticas e/ou identitárias 
ou o próprio desempenho. E essa representação muitas vezes não é convertível numa segunda meta-representação, reificadora da primeira experiência (ibidem: 300 ).

Isso significa que a oposição entre pura presença e desaparecimento não deve ser entendida como um dado positivo da performance (seu compromisso ontológico, no caso de Phelan), mas sim como coloca Schneider (op. cit.: I46), para quem a performance vem "como um meio no qual o desaparecimento negocia, talvez se torne, materialidade. Isto é, desaparecimento é passado adiante. Como materialidade". A performer Eleonora Fabião (2019: 49, grifo nosso) também propõe "se o efêmero denota desaparição e ausência (predicando, então, que em um certo momento algo esteve inteiramente dado à vista) a precariedade denota a incompletude de toda aparição como sua condição constitutiva".

Dessa forma, ao contrário de uma discussão (cada vez mais anacrônica) que se centra sobre especificidades de linguagens artísticas e que visa o encontro de uma ontologia, recolocar a repetição como dado inerente da performance (sempre pela perspectiva da incompletude), possa retomar algo que estava no centro dessas práticas na segunda metade do século $X X$ : seu horizonte utópico em "pensar em performance mais do que como um meio, além de sua vivacidade e efemeridade, e sim como uma série de questões e reflexões sobre como a arte media relações sociais entre pessoas" (COSTINAS; JAVENSKI, 20|4: 8). Dessa forma, a performance não advoga pelo valor do encontro e das trocas presenciais, mas sim detecta e evidencia o caráter instável deles, sempre entre inauguração e repetição. Talvez a partir dessa leitura, sem fetichizar a linguagem, possamos pensar na real necessidade de práticas da performance para a reinvenção de museus e arquivos públicos.

\section{Referências}

AUSLANDER, Philip. A performatividade da documentação da performance. In: Hay em Portugués? n 2, Florianópolis, 2013.

AUSTIN, John Langshaw. Quando Dizer é Fazer: Palavras e Ação, Porto Alegre: Artes Médicas, 1990.

BISHOP, Claire. Artificial hells: Participatory art and the politics of spectatorship. Londres/Nova lorque:Verso Books, 2012.

COSTINAS, Cosmin; JAVENKSI, Ana (ed), Is the Living Body the Last Thing Left Alive? The New Performance Turn, Its Histories and Its Institutions. Belim: Sternberg Press/ Hong Kong: Para Site, 2018.

DE DUVE, Thierry. Performance here and now: Minimal art, a plea for a new genre of theatre. In: Open Letter, v. 5, p. 5-6, 1983.

DERRIDA, Jacques; FREUD, Sigmund. Mal de Arquivo: uma impressão freudiana. Rio de Janeiro: Relume Dumará, 200 I.

FABIÃO, Eleonora. Performance y precariedade. In: KUNST, Bojana et al. In: El tiempo es lo único que tenemos: actualidad de las artes performativas. Buenos Aires: Caja Negra. 2019. 
FÉRAL, Josette. Além dos limites: teoria e prática do teatro. São Paulo: Perspectiva, 2015.

JONES, Amelia. Presença in Absentia: a experiência da performance como documentação. Revista Performatus, v. I, n. 6, 2013.

LEPECKI,Andre. Dance, choreography and the visual: elements for a contemporary imagination. In: COSTINAS, Cosmin; JAVENKSI, Ana (ed), Is the Living Body the Last Thing Left Alive? The New Performance Turn, Its Histories and Its Institutions. Belim: Sternberg Press/Hong Kong: Para Site, 2018.

LEPECKI, André. Singularities: Dance in the age of performance. Lodres/Nova lorque: Routledge, 2016.

MELIN, Regina. Performance nas Artes Visuais. Rio de Janeiro: Zahar, 2008.

PHELAN, Peggy. The ontology of performance: representation without reproduction. In: Unmarked: the politics of performance. Londres/Nova lorque: Routledge, 2003. p. I55-I75.

REBENTISCH, Juliana et al. Autonomia? Autonomia! Experiência estética nos dias de hoje. In: Urdimento - Revista de Estudos em Artes Cênicas, v. 3, n. 30, p. I0I-III, 2017.

ROACH, Joseph R. Cities of the dead: Circum-Atlantic performance. Cambridge: Columbia University Press, 1996, p. 3.

SARDO, Delfim. O Exercício Experimental da Liberdade: Dispositivos da arte no século XX. Lisboa: Orfeu Negro, 2017.

SCHECHNER, Richard. O que é performance? Tradução de R.L. Almeida, publicado sob licença creativa commons, classe3.Abril de 20II. Disponível em: <http:// performancesculturais.emac.ufg.br/uploads/378/original_O_QUE_EH_PERF_ SCHECHNER.pdf>. Acesso em 21 jul. 2020.

SCHECHNER. Richard. $O$ que é Performance. In: $O$ percevejo, Revista de Teatro, Crítica e Estética. Estudos da Performance. Rio de Janeiro: UNIRIO, 2003, ano II, n.I2.

SCHNEIDER, Rebecca. Performance remains. In: JONES, Amelia; HEATHFIELD, Adrian (Ed.). Perform, Repeat, Record: Live Art in History. Bristol: Intellect Books, 20I2, p. I4I

WOOD, Catherine. Performance in Contemporary Art. London:Tate, 2018. 